\title{
Effects of musical improvisation as a cognitive and motor intervention for the elderly
}

\author{
Efeitos da improvisação musical como intervenção \\ cognitiva e motora para idosos
}

\author{
Marcelo Rabello dos SANTOS ${ }^{1}$ ID 0000-0001-6597-9422 \\ Monique Siebra KRUG ${ }^{2}$ iD 0000-0002-5421-0615 \\ Michel Rasche BRANDÃO2 ID 0000-0002-7952-9139 \\ Victória Silva de LEON² (D) 0000-0002-9802-2739 \\ Júlia Cenci MARTINOTTO² (DD)0000-0001-5952-806X \\ Júlia Delgado da FONSECA ${ }^{3}$ (ID) 0000-0002-2226-1952 \\ Alissa Costa BRASIL ${ }^{4}$ iD) 0000-0001-5927-3247 \\ Andréa Guedes MACHADO5 (iD) 0000-0003-2939-2223 \\ Alcyr Alves de OLIVEIRA' ${ }^{1}$ (ID) 0000-0002-0747-7835
}

\begin{abstract}
Music has been debated as a positive factor for the health of elderly people. In a randomized study, the researchers compared an intervention based on percussion and musical improvisation with a choir activity. The objective was to

1 Universidade Federal de Ciências da Saúde de Porto Alegre, Programa de Pós-Graduação em Psicologia e Saúde. R. Sarmento Leite, 245, Centro Histórico, 90050-170, Porto Alegre, RS, Brasil. Correspondence to: A.A. OLIVEIRA. E-mails: <alcyr.oliveirajr@gmail.com>, <marcelors@ufcspa.edu.br>.

2 Universidade Federal de Ciências da Saúde de Porto Alegre, Curso de Psicologia, Departamento de Psicologia. Porto Alegre, RS, Brasil.

3 Universidade Federal de Ciências da Saúde de Porto Alegre, Curso de Nutrição, Departamento de Nutrição. Porto Alegre, RS, Brasil.

${ }^{4}$ Universidade Federal de Ciências da Saúde de Porto Alegre, Curso de Fonoaudiologia, Departamento de Fonoaudiologia. Porto Alegre, RS, Brasil.

5 Universidade Federal de Ciências da Saúde de Porto Alegre, Programa de Pós-Graduação em Ciências da Reabilitação. Porto Alegre, RS, Brasil.

Article based on the dissertation of M.R. SANTOS, entitled "Efeitos da improvisação musical como intervenção cognitiva e motora para idosos". Universidade Federal de Ciências da Saúde de Porto Alegre, 2019.
\end{abstract}

$\boldsymbol{\nabla} \boldsymbol{\nabla} \boldsymbol{\nabla}$

How to cite this article

Santos, M. R., Krug, M. S., Brandão, M. R., Leon, V. S., Martinotto, J. C., Fonseca, J. D., .. Oliveira, A. A. (2021). Effects of musical improvisation as a cognitive and motor intervention for the elderly. Estudos de Psicologia (Campinas), 38, e190132. https://doi. org/10.1590/1982-0275202138e190132 
investigate whether improvisation would influence the executive functioning and motor skills of healthy elderly people. A set of instruments for psychological and motor assessment was used before and after the procedure. Differences were found in the performance of the participants of the improvisation group in the Clock Drawing Test suggesting possible gains in executive function. There were gains, regardless of the group, in part A of the Trail Making Test, which indicates a sustained attention. No evidence of motor effects was found in this study. The results suggest that musical activities can contribute to the prevention of cognitive decline caused by aging.

Keywords: Cognition; Health of the elderly; Motor activity; Music.

\section{Resumo}

A música tem sido discutida como fator promotor da saúde do idoso. Em um estudo randomizado, uma intervenção baseada em exercícios de percussão e improvisação foi comparada a uma atividade de canto coral. O objetivo foi investigar os efeitos sobre o funcionamento executivo e motor de idosos saudáveis. Um conjunto de instrumentos de avaliação psicológica e motora foi aplicado antes e depois da intervenção. Foram encontradas diferenças no desempenho do grupo de improvisação no Teste de Desenho do Relógio sugerindo possíveis ganhos executivos. Houve ganhos independentes de grupo na parte $A$ do Teste de Trilhas, que avalia a atenção sustentada. Não foram verificadas evidências de efeitos motores. Os resultados indicam que atividades musicais podem contribuir na prevenção do declínio cognitivo decorrente do envelhecimento.

Palavras-chave: Cognição; Saúde do idoso; Atividade motora; Música.

The world population is growing older: by 2060, in Brazil, it is estimated that there will be 66 elderly for every 100 active people and only 21.6 children for the same group (Oliveira, 2016). The 30 million elderly milestone was exceeded in 2017 and the population group with the highest growth rate is that of people over 80 (Minayo \& Firmo, 2019). As Norton, Matthews, and Brayne (2013) point out, a consequence of the global aging trend will be the dramatic increase in the prevalence of dementia. Wahl et al. (2019) express the urgency in developing interventions that prevent cognitive decline and its subsequent impairment. Klimova, Valis, and Kuca (2017) highlight several non-pharmacological interventions, such as physical exercises and piano lessons, that have proven beneficial in cognitive domains such as executive functioning, attention, and memory.

A new understanding of aging emphasizes the possibility of preservation and even gains in the cognitive domain (Neri \& Yassuda, 2004). Cespón, Miniussi, and Pellicciari (2018) indicate that there is a growing body of evidence that older people have a potential for neuroplasticity. Music is being discussed as a way to produce neuroplastic changes that would delay cognitive decline (Garrido, Dunne, Perz, Chang, \& Stevens, 2018; Gleizer \& Rábanos, 2017). Practicing musical instruments stimulate not only the auditory cortex, but areas of the brain involving attention, memory, motor function, and emotional processing (Särkämö, 2018).

The assumption that music can promote cognitive benefits or, more precisely, that the effects of music training can be transferred to non-musical domains still lacks support, either by the absence of a theoretical model that explains this transfer or by the fragility of the evidence produced so far (Sala \& Gobet, 2017). One hypothesis currently under study is that the Executive Functions (EF) - especially the inhibitory control -, are the processes that could explain the transference of musical training to non-musical skills (Moreno \& Farzan, 2015).

Although there is divergence among authors regarding the cognitive processes understood among the EF, selective attention, inhibitory control, working memory, cognitive flexibility, and monitoring can be

2 included among them (Godoy, Dias, Trevisan, Menezes, \& Seabra, 2010). There is also a correlation between 
EF and health indicators of the elderly, such as walking speed (Taylor et al., 2017). Recently, practicing musical improvisation and percussion has been related to executive gains and discussed as promoters of cognitive health for the elderly (Biasutti \& Mangiacotti, 2017; Kim \& Yoo, 2019).

Pressing (1987) explains the practice of improvisation through a three-step model: input (sensory organs); processing and decision making (central nervous system); and motor output. The author stresses that it is a practice that requires constant monitoring (auditory, visual, tactile, and proprioceptive) in order to allow the improviser to form cognitive representations and thus manage the design of the subsequent actions. Thus, musical improvisation differs from a fixed performance, which is based entirely on a previously established framework (memory or sheet music). Beaty (2015), relying on the model by Pressing (1987), argues that recent behavioral and neuroimaging evidences suggest that improvisation can recruit areas of the brain related to cognitive processes of broader scope, such as the anterior cingulate cortex, associated with EF as monitoring and decision making.

The aim of this study was to assess the effects of an intervention based on improvisation and percussion activities on elderly individuals. Unlike other studies of similar scope, such as the one by Biasutti and Mangiacotti (2017), in which the effects of musical activities were compared to the effects of physical activities, in this study the effects of two different musical protocols were compared: one focused on improvisation and another on fixed performance. The researchers sought to understand the difference in the effects of these modalities of musical engagement, based on the hypothesis that relates improvisation and executive functioning.

\section{Method}

\section{Participants}

The study enrolled 28 healthy elderly people, recruited by snowball sampling (Vinuto, 2014). The intervention was carried out at the headquarters of an elderly association located in the metropolitan area of a Brazilian capital, with active participants in the local community. For developing countries, the age of 60 is recommended as the threshold between adulthood and old age (Fechine \& Trompieri, 2012).

The inclusion criteria were: (1) 60 years or older; (2) not currently participating in musical activities promoted by the local elderly association. Exclusion criteria: (1) score below the cut-off point in the Mini Mental State Examination (MMSE) (Caramelli \& Nitrini, 2000), as described in Measures; (2) presence of motor difficulties that would interfere in the performance of the activities; and (3) presence of neurodegenerative diseases already diagnosed.

\section{Procedures}

All participants were informed about the research through clarification meetings held by the researchers. A total of 37 volunteers expressed their interest in participating in the study and signed the Consent Form in accordance with decision $n^{\circ} 2.865 .851$ by the Research Ethics Committee of the Universidade Federal de Ciências da Saúde de Porto Alegre (UFCSPA, Federal University of Health Sciences of Porto Alegre).

Figure 1 presents the flowchart of the participants through the study selection process. An initial screening allowed to determine that 31 of the 37 volunteers met the initial criteria. These participants were randomized into two groups: percussion and musical improvisation (experimental: $n=15$ ) and choir (control: $n=16$ ). Of the remaining six people, five obtained scores below the cut-off point in the MMSE and one had 
already been diagnosed with a neurodegenerative disease. The study was inclusive: all those who volunteered had the opportunity to participate in musical activities. Thus, the six volunteers that did not meet the criteria were invited to participate in the control group (choir) but did not have their data collected.

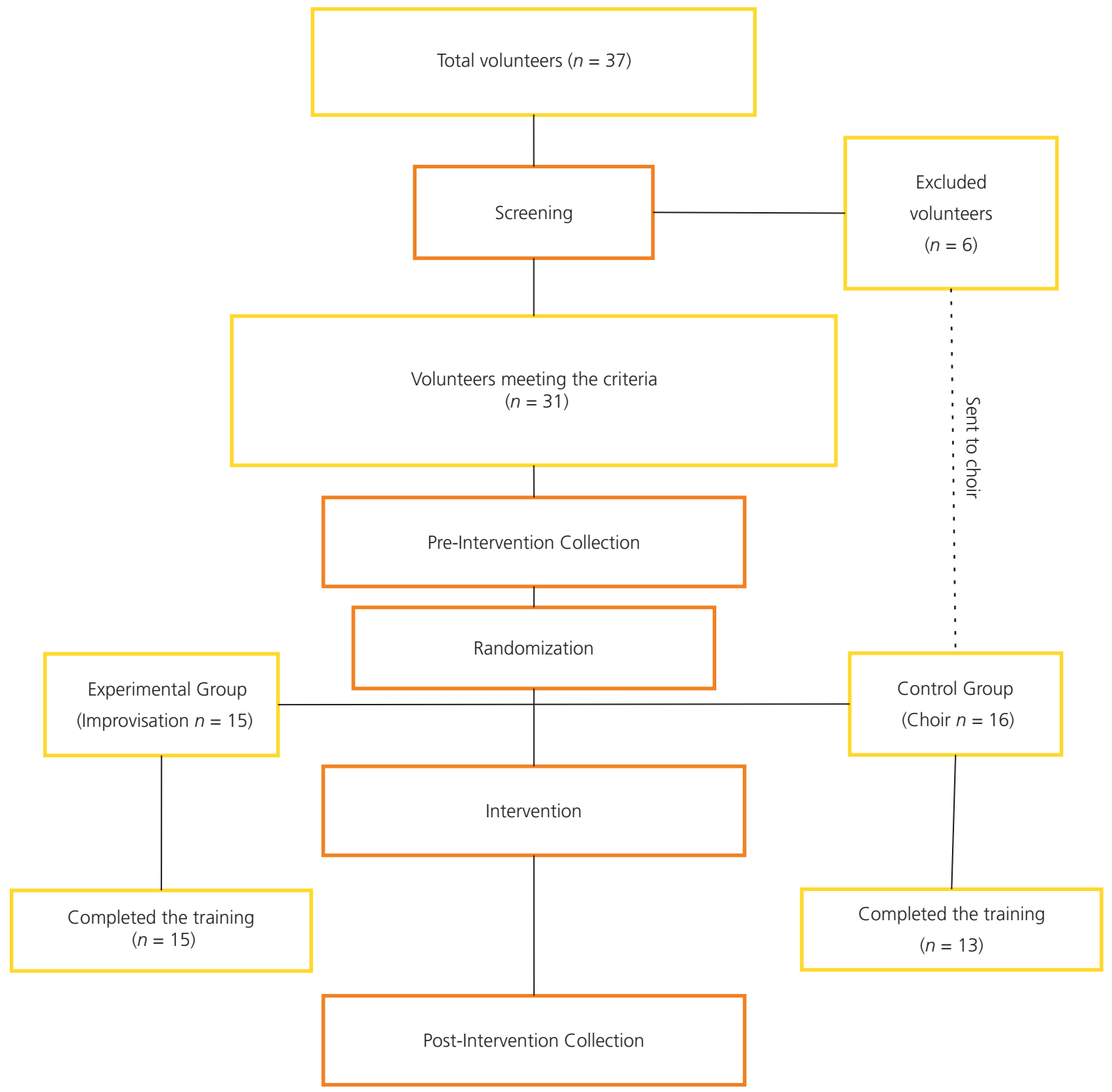

Figure 1. Flowchart of the participants.

Table 1 shows the characterization of the participants from the data collected in the initial screening. No significant sociodemographic differences were found between the experimental and control groups. The musical engagement, obtained through the adapted version of the Music Use Questionnaire (Chin \& Rickard, 2012) allowed the comparison of three indices related to different past aspects of musical life - listening, practicing, and formal training - without significant differences being found between the groups. Finally, the mean scores of the MMSE of both groups indicate the 4 comparability of the groups in terms of global cognition. 


\begin{tabular}{|c|c|c|c|c|c|}
\hline \multirow{3}{*}{$\begin{array}{l}\text { Characterization variables } \\
\text { Age [Mean (SD)] } \\
\text { Years of formal education - [Median (Q1; Q3)] }\end{array}$} & \multicolumn{2}{|c|}{ Improvisation $n=15$ Exp. Group } & \multicolumn{2}{|c|}{ Choir $n=13$ Control Group } & \multirow{2}{*}{$\frac{p \text {-value }}{0.629^{*}}$} \\
\hline & 68.40 & $(5.98)$ & 67.31 & $(5.79)$ & \\
\hline & 9 & $(4 ; 16)$ & 7 & $(4.5 ; 9)$ & $0.235^{* *}$ \\
\hline $\begin{array}{l}\text { Sex } \\
\quad[\text { woman } n(\%)] \\
{[\operatorname{man} n(\%)]}\end{array}$ & $\begin{array}{c}10 \\
5\end{array}$ & $\begin{array}{l}(66.7) \\
(33.3)\end{array}$ & $\begin{array}{c}12 \\
1\end{array}$ & $\begin{array}{r}(92.3) \\
(7.7)\end{array}$ & $0.173^{* * *}$ \\
\hline $\begin{array}{l}\text { Relationship status } \\
\text { [married } n(\%)] \\
\text { [widow(er) } n(\%)] \\
\text { [Divorced/separated } n(\%)] \\
\text { [Dating } n(\%)]\end{array}$ & $\begin{array}{l}7 \\
4 \\
2 \\
2\end{array}$ & $\begin{array}{l}(46.7) \\
(26.7) \\
(13.3) \\
(13.3)\end{array}$ & $\begin{array}{l}6 \\
6 \\
1 \\
0\end{array}$ & $\begin{array}{r}(46.2) \\
(46.2) \\
(7.7) \\
(0.0)\end{array}$ & $0.443^{* * *}$ \\
\hline $\begin{array}{l}\text { Musical engagement }{ }^{1} \text { [Median (Q1; Q3)]: } \\
\text { Audition index } \\
\text { Practice index } \\
\text { Training index } \\
\text { MMSE }^{2} \text { [Mean (SD)] }\end{array}$ & $\begin{array}{c}6 \\
0.33 \\
0 \\
26.73\end{array}$ & $\begin{array}{c}(2 ; 10) \\
(0 ; 0.85) \\
(0 ; 0) \\
(1.79)\end{array}$ & $\begin{array}{c}10 \\
1.06 \\
0 \\
27.31\end{array}$ & $\begin{array}{r}(4 ; 12.5) \\
(0 ; 2.75) \\
(0 ; 1.5) \\
(1.97)\end{array}$ & $\begin{array}{l}0.072^{* *} \\
0.363^{* *} \\
0.786^{* *} \\
0.427^{*}\end{array}$ \\
\hline
\end{tabular}

Note: " Student's t-test; ${ }^{* *}$ Mann-Whitney test; ${ }^{* * *}$ Chi-Squared test. ${ }^{1}$ MUSE: Music Use Questionnaire; ${ }^{2}$ MMSE: Mini-Mental State Examination. SD: Standard Deviation.

In the pre-intervention data collection stage, psychological and motor tasks were carried out. It was conducted in the two-week period before the start of the musical activities. It was performed by researchers linked to the Psychology course of UFCSPA who received specific training regarding the activities employed.

The musical activities were conducted by a researcher with specific training in music and lasted eight weeks, with one hour of activity per week. All the participants of the experimental group completed the musical training. Of the 16 people assigned to the control group, one did not complete the training and two communicated their exclusion due to personal problems, resulting in $n=13$ for the control group.

The post-intervention collection was performed in the same place as the pre-intervention collection, by the same researchers, in the same period (up to two weeks after the end of the musical intervention). One participant of the control group had difficulties, due to vision problems, in performing some psychological tasks, which were not completed. Thus, Tables 2 and 3 point towards this group $(n=12)$.

Finally, at the end of the study activities, the participants of each group were invited to continue their musical engagement in the modality of their preference. Percussion and improvisation activities, as well as choir singing, continued to be offered, allowing the participants of the choir to experience improvisation and vice-versa.

\section{Instruments}

The following instruments were used in the initial screening.

Structured Interview: Collection of socio-demographic data and health-related information.

Mini Mental State Examination (MMSE) - (Brucki, Nitrin, Caramelli, Bertolucci, \& Okamoto, 2003): Cognitive decline screening instrument. The adopted cut-off points were: 18 (illiterate participants), 21 (participants between one and three years of schooling), 24 (participants between four and seven years of schooling) and 26 (participants with more than seven years of schooling) (Caramelli \& Nitrini, 2000).

Musical engagement interview - The original instrument, the Music Use Questionnaire (Chin \& Rickard, 2012): It was translated into Portuguese and adapted to the interview format by one of the researchers. It generates three indices. The musical listening index reflects the time dedicated over a week to listening to 
music (radio, concerts etc.). The musical practicing index refers to the time dedicated to more active forms of musical engagement, such as singing or dancing. The musical training index relates to formal musical practicing.

The following psychological and motor tasks were employed in data collection before and after the musical intervention:

Trail Making Test (TMT) - (Vazzana et al., 2010): It assesses attention and cognitive flexibility. The result of the test corresponds to the total time the task took to be completed. Shorter times indicate better performances.

Verbal Fluence Test (VFL) - (Rodrigues, Yamashita, \& Chiappetta, 2008): The participant is asked to produce, in one minute, words beginning with the letter " $f$ " (phonemic fluence) and names of animals (semantic fluence). The score equals the number of words produced. It assesses semantic memory, information retrieval, thought organization, and strategies for word selection.

Clock Drawing Test (CDT) - (Sunderland et al., 1989): The scores correspond to the accuracy in details, such as the positioning of the hands, with a maximum score of ten. It assesses visuospatial ability, mental representation, and planning.

Five Digits Test (FDT) - (Campos, Silva, Florêncio, \& Paula, 2016): It assesses the executive functioning through reading, counting, choosing, and alternating tasks involving the numbers 1 to 5 . Based on the Stroop effect.

Rivermead Behavioral Memory Test (RBMT-3) - (Steibel, 2016): It generates a general memory index from tasks that assess visual, verbal, spatial, and prospective memory as well as guidance and learning.

Timed Up and Go (TUG) - (Wamser et al., 2015): It assesses functional mobility and risk of falling. The score corresponds to the time taken for the participant to get up from a chair, walk a predetermined path and sit down again.

Finger Tapping Test (FTT) - (Ashendorf, Vanderslice-Barr, \& McCaffrey, 2009): Assesses motor coordination and manual dexterity. It was performed through the CNS Tap application for Android Smartphones. The participant is asked to tap his finger on the phone screen as fast as he can over 10 seconds. The number of beats is his or her score. In this study, the index finger of both hands was used.

\section{Musical Activities}

The protocol of the experimental group consisted of eight weekly meetings of 60 minutes. The activity was held in a room with chairs arranged in a circle. In the center of the room, there was a box with 15 easy-to-handle percussion musical instruments. A blackboard was available, as well as basic sound equipment, to allow recording and listening of results. The conductor of the session also had a musical keyboard to support and propose activities.

The experimental protocol was based on the first three steps of the proposed Kratus model (1991). For the author, improvisational practice begins with exploration: the participants discover the sound potentialities of musical instruments, without having yet established the predictability relationships between their manipulation and their corresponding sound. In the next step, the relations between sound and movement start to be configured. In the third step, properly improvisatory, the participants are more confident with their instruments and more aware of the collective dimension: a concern with the musical result itself arises.

The experimental protocol adopted consisted of four stages: A, B, C, and D. Stage A corresponded to the exploration of the instruments: the initial step of the Kratus model (1991). According to Schafer's suggestion (1992), the participants were invited to discover a new instrument in the box, discover three

6 different sounds in this instrument and present the result to the other participants. 
Stages B and C corresponded to the second step of the Kratus model (1991). The exercises of stage B emphasized the development of the sense of beat and other rhythmic abilities. Each participant was invited to walk according to the pulse produced by a colleague with an instrument, and variations were proposed on the imitation game and the question and answer game (Costa, 2016). In stage C, it was sought to make the group aware of the group's collective dimension. Musical textures, such as pointillism, were proposed and executed by the group with the help of markings on the blackboard for a better understanding of the desired sound results, according to Schafer's proposals (1992). Also introduced in stage C was the conductor's game, inspired by soundpainting (Coskuner \& Stalheim, 2020), in which one of the participants guided aspects of the other participants' musical performance through gestures.

Stage D corresponds to the third step of the Kratus model (1991), i.e. where there is production of musical pieces. Previously employed techniques - such as the use of soundpainting or the blackboard -, remained on the agenda. The first activity proposed for this stage was the composition of a soundtrack for a story (Silva, 2020), which allows a musical piece to be structured from a pre-existing narrative. The first story intended to represent with sounds the journey of a man who leaves the forest environment towards a large city and then returns. The story was told beforehand to the participants, who were encouraged to plan beforehand the musical actions they thought most appropriate to each part of the narrative. The exercise was repeated several times. Each result was recorded and presented to the participants, who were able to listen, express their opinions and refine their performance. Then, new narratives or scripts were introduced by the participants themselves. Finally, free improvisation was practiced, in which the structural details of the piece were also the result of improvisation.

The four stages were distributed over the eight session as follows: sessions 1 and 2 were divided between activities of stages $A$ and $B$ ( 30 minutes for each stage). Sessions 3 and 4 were divided in the same way between stages $B$ and $C$, and sessions 5 and 6 between stages $C$ and $D$. The final sessions, 7 and 8 , were entirely dedicated to stage $D$.

The choir singing activity, which is non improvisatory, was performed as a control. In literature, choir singing is being discussed as a promoter of quality of life (Skingley, Martin, \& Clift, 2016), but it has not been directly associated with cognitive domains. The choir activity was carried out in the same room as the experimental activity, with similar spatial organization, by the same researcher and for the same period: weekly rehearsals of 60 minutes for eight weeks.

The structure of each of the sessions followed the traditional practices for elderly groups (Almeida, 2013): the initial 15 minutes were dedicated to body and vocal warm-up and the remaining time was used to work on the repertoire through a process of repetition and uniformization. The repertoire, worked over the eight weeks, consisted of four known and accessible songs from the Brazilian pop music repertoire.

All the songs of the choir group were rehearsed with the support of the musical keyboard to improve harmony, and the participants received the printed lyrics. The arrangements were made by the researcher responsible for conducting the sessions and guiding the execution of the pieces. As in the experimental group, the participants were concerned with the increasing complexity throughout the sessions. Gradually, longer parts of the songs were worked until it was possible to interpret the whole piece. From the harmonic point of view, the first piece brought only unison and octaves, while the fourth already brought segments in three voices.

\section{Blindings}

The participants were not informed until the end of the study about the fact that the improvisation group was the experimental one and the choir the control one. The team responsible for collecting the data 
before and after the intervention had no contact with the activities of the intervention. At the time of collection, the responsible team was blinded to the group of participants. The first collection was performed before randomization, that is, before the groups were assigned. Before the second collection, the participants were advised not to comment on the activity in which they were engaged. The researcher who was responsible for the intervention was blinded to the participants' data throughout the data collection and compilation process. The researcher who was responsible for the randomization, aware of the allocation of participants among the groups, was an individual from outside the group responsible for conducting this research.

\section{Data Analysis}

The statistical analysis of the data was performed through the IBM ${ }^{\circledR}$ SPSS ${ }^{\circledR}$ Statistic 18 Software, with the support of the Núcleo de Apoio ao Pesquisador (Research Support Nucleus) of UFCSPA. The Generalized Estimating Equation Model was used to detect differences between groups in their pre- and post-intervention scores.

\section{Results}

A significant difference was found between the experimental group and the control group in the performance of the CDT, that assesses visuospatial and planning abilities ( $p=0.013$ for time vs group interaction). The increase in the CDT score of the experimental group was $1.33\left(p_{\text {value }}=0.043\right.$ - Bonferroni Test), while there was a non-significant decrease for the control group of 0.69 ( $p_{\text {value }}=0.148$ - Bonferroni Test). It was also found a significant independent variation between groups in the TMT A score (the first part of the TMT), focused on sustained attention. So, the sample as a whole presented significant performance improvements in the TMT A ( $p=0.03$ for the time factor). No significant differences were found in the Verbal Fluency Test (VFT) nor in the RBMT-3 (memory test). Table 2 summarizes the results of the CDT, TMT A, VFT, and RBMT-3 psychological tasks.

Table 3 presents the scores of the tasks that make up the FDT, which assesses aspects of executive functioning, such as flexibility and inhibition. The Z-scores of each participant were calculated with reference to the normative data of the Brazilian population (Campos et al., 2016). The only significant difference was the reduction of errors in the counting task, regardless of group ( $p=0.029$, time factor). The results of the motor tasks are presented in Table 4. No significant differences were found in the TUG, which assesses the risk of falling, nor in the FTT, assessing manual dexterity.

Table 2

Pre-intervention and post-intervention scores of psychological tasks

\begin{tabular}{|c|c|c|c|c|c|c|c|c|c|c|c|}
\hline \multirow{2}{*}{ Measures } & \multicolumn{4}{|c|}{$\begin{array}{c}\text { Improvisation } n=15 \\
\text { Experimental Group Measures }\end{array}$} & \multicolumn{4}{|c|}{$\begin{array}{l}\text { Choir } n=12 \\
\text { Control Group }\end{array}$} & \multicolumn{3}{|c|}{$p$-value* } \\
\hline & \multicolumn{2}{|c|}{ Pre- } & \multicolumn{2}{|c|}{ Post } & \multicolumn{2}{|c|}{ Pre- } & \multicolumn{2}{|c|}{ Post } & $\begin{array}{l}\text { Time } \\
\text { factor }\end{array}$ & $\begin{array}{l}\text { Group } \\
\text { factor }\end{array}$ & $\begin{array}{l}\text { Time vs Group } \\
\text { Interaction }\end{array}$ \\
\hline$\overline{\mathrm{CDT}^{1}[\text { mean }(S D)]}$ & 5.47 & $(1.85)$ & 6.8 & $(2.24)$ & 6.77 & $(1.30)$ & 6.08 & $(1.89)$ & 0.402 & 0.554 & $0.013^{* *}$ \\
\hline $\mathrm{TMT}^{2} \mathrm{~A}[\operatorname{mean}(S D)]$ & 66.44 & $(29.58)$ & 60.31 & $(20.94)$ & 54.46 & $(14.70)$ & 50.36 & $(16.16)$ & $0.030^{* * *}$ & 0.122 & 0.820 \\
\hline $\mathrm{VFL}^{3,4}[$ mean $(S D)]$ & & & & & & & & & & & \\
\hline - Phonemic & 11.93 & $(3.47)$ & 12.00 & $(4.00)$ & 12.77 & $(4.30)$ & 11.83 & (3.38) & 0.377 & 0.796 & 0.307 \\
\hline - Semantic & 17.67 & (5.29) & 17.07 & $(4.85)$ & 15.00 & $(4.94)$ & 15.83 & $(4.86)$ & 0.833 & 0.221 & 0.337 \\
\hline $\mathrm{RBMT}^{5}[$ mean $(S D)]$ & 88.20 & (15.09) & 88.86 & (15.95) & 88.83 & $(14.16)$ & 89.83 & $(6.65)$ & 0.783 & 0.861 & 0.945 \\
\hline
\end{tabular}

Note: *Generalized Estimating Equation Model; ${ }^{* *}$ Significant difference between groups; ${ }^{* * *}$ Independent group effect. ${ }^{1}$ Clock Drawing Test. ${ }^{2}$ Trail Making Test. ${ }^{3}$ Verbal Fluence Test. ${ }^{4} n=14$ for experimental group due to technical problems. ${ }^{5}$ Rivermead Behavioral Memory Test. 
Table 3

$F D T^{1}$ : Z-score means ${ }^{2}$

\begin{tabular}{|c|c|c|c|c|c|c|c|}
\hline \multirow[t]{2}{*}{ Measures } & \multicolumn{2}{|c|}{$\begin{array}{l}\text { Improvisation } n=15 \\
\text { Experimental Group }\end{array}$} & \multicolumn{2}{|c|}{$\begin{array}{l}\text { Choir } n=12 \\
\text { Control Group }\end{array}$} & \multicolumn{3}{|c|}{$p$-value* } \\
\hline & Pre- & Post & Pre- & Post & Factor Time & Factor Group & Time vs Group Interaction \\
\hline Reading & 0.66 & 0.29 & 0.22 & -0.09 & 0.115 & 0.216 & 0.927 \\
\hline Errors & 1.98 & -0.07 & 2.50 & 0.83 & 0.124 & 0.534 & 0.869 \\
\hline Counting & 0.47 & 0.47 & 0.33 & 0.07 & 0.264 & 0.271 & 0.244 \\
\hline Errors & 1.24 & -0.08 & 0.50 & 0.22 & $0.029^{* *}$ & 0.697 & 0.153 \\
\hline Choosing & 0.10 & 0.11 & 0.01 & -0.17 & 0.552 & 0.476 & 0.532 \\
\hline Errors & 2.00 & 0.72 & 1.31 & 0.63 & 0.150 & 0.695 & 0.664 \\
\hline Alternating & 0.36 & -0.11 & -0.31 & -0.37 & 0.094 & 0.072 & 0.191 \\
\hline Errors & 1.77 & 1.58 & 1.15 & 0.56 & 0.265 & 0.344 & 0.575 \\
\hline Flexibility & 0.17 & -0.24 & -0.32 & -0.53 & 0.095 & 0.120 & 0.577 \\
\hline Inhibition & -0.29 & 0.00 & -0.13 & -0.35 & 0.864 & 0.744 & 0.214 \\
\hline
\end{tabular}

Note: "Generalized Estimating Equation Model; ${ }^{* *}$ Group independent effect. ${ }^{1}$ Five Digits Test. ${ }^{2}$ Calculated using normative data from the Brazilian population.

Table 4

Scores of pre- and post-intervention motor tasks

\begin{tabular}{|c|c|c|c|c|c|c|c|c|c|c|c|}
\hline \multirow[b]{2}{*}{ Measures } & \multicolumn{4}{|c|}{ Improvisation $n=15$ Experimental Group } & \multicolumn{4}{|c|}{ Choir $n=13$ Control Group } & \multicolumn{3}{|c|}{$p$-value* } \\
\hline & \multicolumn{2}{|c|}{ Pre- } & \multicolumn{2}{|c|}{ Post } & Pre- & \multicolumn{3}{|c|}{ Post } & \multirow{2}{*}{$\begin{array}{l}\begin{array}{c}\text { Time } \\
\text { Factor }\end{array} \\
0.084\end{array}$} & \multirow{2}{*}{$\begin{array}{l}\text { Group } \\
\text { Factor } \\
0.369\end{array}$} & \multirow{2}{*}{$\begin{array}{c}\begin{array}{c}\text { Time vs } \\
\text { Group } \\
\text { Interaction }\end{array} \\
0.91\end{array}$} \\
\hline $\begin{array}{l}\mathrm{TUG}^{1}[\text { mean }(S D)] \\
\mathrm{FTT}^{2}[\text { mean }(S D)]\end{array}$ & 10.41 & $(1.70)$ & 9.90 & $(2.08)$ & 11.01 & $(1.51)$ & 10.40 & (1.96) & & & \\
\hline Right index finger & 41.21 & $(10.83)$ & 47.13 & $(8.91)$ & 45.85 & $(12.91)$ & 45.83 & $(5.56)$ & 0.169 & 0.557 & 0.167 \\
\hline Left index finger & 37.00 & (13.06) & 35.73 & (9.90) & 43.15 & (9.89) & 38.66 & (10.18) & 0.226 & 0.146 & 0.706 \\
\hline
\end{tabular}

Note: *Generalized Estimating Equation model. ${ }^{1}$ Test Up and Go. ${ }^{2}$ Finger Tapping Test.

SD: Standard Deviation.

\section{Discussion}

As Sala and Gobet (2017) point out, transference occurs when a skill acquired in a certain area is generalized to other areas or results in gains in more general cognitive domains. When discussing the possibility of transference effects caused by musical training, they argue that the motivation resulting from the novelty of musical activity may, by itself, explain such effects. They advise that experiments involving musical activities should be controlled from equally exciting activities. In this study, the comparison was made between two musical activities, one improvisatory and the other presumably as motivating as the first, but non improvisatory. The aim was to allow any observed differences between groups to be attributed to differences between the musical activities.

The significant difference between groups in the performance of the CDT (Table 2) suggests the possibility of an improvisational training transfer effect. The findings of Biasutti and Mangiacotti (2017) also suggest the association between performance improvement in the CDT and practicing musical improvisation, discussed by the authors in terms of possible executive gains. More specifically, planning skills (which are part of the EF) seem to be involved: the act of drawing the clock implies, on the part of the individual taking the test, a prior planning of the steps involved (Paula, Miranda, Moraes, \& Malloy-Diniz, 2013). Likewise, the activities carried out by the participants of the experimental group involved the prior planning of actions, especially in the final stage (D) of the protocol.

An important remark: the experimental group presented, in the pre-intervention collection, smaller mean scores in the CDT than the control group. This fact could be interpreted as evidence that the experimental 
group presented a greater initial impairment in some cognitive domains than the control group, even if both groups were comparable in global cognition (as indicated by the results of the MMSE performed in the initial screening). Thus, it might be possible to question what effect choir singing would have had on the control group if this group had presented a greater initial impairment.

For Medina and Barraza (2019), there is evidence that practicing music produces gains for the attentional system, through a potential transference effect between training and inhibitory control, which is one of the EF. The research findings of Seinfeld, Figueroa, Ortiz-Gil, and Sanchez-Vives (2013) associate musical training and the reduction of attentional interference in the elderly, that is, a better inhibition and selection of stimuli, which are processes of inhibitory control. In this research, the FDT was used to assess the attentional interference. No effects were found beyond a significant reduction of errors regardless of the group. Two issues may be involved in this outcome. One is the protocol of musical activities applied by Seinfeld et al. (2013), which was aimed at learning to read musical scores for piano, an activity that possibly involves cognitive dimensions different from those mobilized by the protocols of this study. Another is the fact that different tests were employed, although with the same objective. Seinfeld et al. (2013) employed the Stroop Test while, in this study, the researchers opted for the FDT, appropriate for people of any language and reliable for the Brazilian population (Campos et al., 2016). Perhaps the FDT proved to be less sensitive than the Stroop Test.

Interestingly, the results of the TMT-A, which assesses sustained attention (Alves, Zaninotto, Miotto, Lucia, \& Scaff 2010), suggested that, for this attentional dimension, there have been gains regardless of the group. This finding seems to highlight that both protocols, experimental and control, are collective activities in which the performance necessarily depends on the attention to the actions of other people involved. The Trail Making Test B was also proposed as a task for the participants, but many of them were unable to finish the test properly. Difficulties have been reported with the alphabet sequence, knowledge of which is required in this test. Considering that issues related to the participants' educational level could interfere with the reliability of the results, the results of this task were not analyzed.

Transfer effects between musical training and motor skills of the elderly have also been discussed in literature. Regarding the risk of falling, the time of intervention seems to be determinant. The findings of Trombetti et al. (2011), which indicate that the risk of falling decreased in elderly who perform musical activities (in an effect possibly mediated by the EF), were based on an intervention of six months. The difference in the intervention time may explain, therefore, that no differences were found in the TUG results in this study. Additionally, this sample was composed of "younger" elderly individuals, younger than those in the study of Trombetti et al. (2011), with mean TUG times below 12.4 seconds, i.e., outside the risk assessment (Wamser et al., 2015).

A study by Seinfeld et al. (2013) found gains in manual dexterity in the elderly resulting from playing piano. The FTT, also used in the present study, was employed in this assessment. The protocol employed by these researchers was explicitly bimanual, with exercises for the independence of each finger. The experimental protocol was predominantly one-handed (monomanual), with musical instruments that were easy to handle and aimed for immediate engagement. The difference in the FTT results can be explained, therefore, by the clear differences in the emphasis of motricity between the studies.

Considering the correlation between executive functioning and memory decline (Clarys, Bugaiska, Tapia, \& Baudouin, 2009), it was decided to investigate the effect of the proposed musical activities in the field of memory through an ecological and all-encompassing test, the RBMT3 (Steibel, 2016). The absence of effects detected with this test can be related to what was pointed out by Clark and Warren (2015): the connections between music and memory seem to somehow elude the more general formulations about human memory, pointing to a separate system, as suggested by the paradox of preserved musical memory in certain cases of Alzheimer's disease. 
Another area in which transference effects have been proposed and observed is the one between language and music, although there is no consensual theoretical basis (Slevc, 2012). Thus, it was also decided to observe if musical interventions could translate into specific gains in verbal fluency, a hypothesis that was not confirmed by the evidence produced. Biasutti and Mangiacotti (2017) attribute, in their study with elderly people, the gains in verbal fluency related to scat singing, which is a modality of vocal improvisation. In fact, this modality of improvisation did not integrate the protocol of this study, which was focused on instrumental improvisation.

The data produced by this study give partial support to the hypothesis that musical activities performed by the elderly, especially those of an improvisatory character, may have effects on executive functioning through transfers between training and planning and inhibition functions. The results also seem to support the conception that different modalities of musical training have different effects. Future research is suggested to explore these issues through larger samples and by comparing other forms of musical training and musicrelated activities, such as dancing. Finally, the results reinforce the idea that music can contribute to the prevention of cognitive decline, being an ally in the challenges posed by an aging population.

\section{Contributors}

M. R. SANTOS was responsible for the design and writing of the article. M. S. KRUG, M. R. BRANDÃO, V. S. LEON, J. C. MARTINOTTO, J. D. FONSECA, and A. C. BRASIL contributed to the analysis, discussion of results and revision of the manuscript. A. G. MACHADO contributed to the analysis of the results. A. A. OLIVEIRA was responsible for the study design and final review of the article.

\section{References}

Almeida, M. C. P. (2013). O canto coral e a terceira idade: o ensaio como momento de grandes possibilidades. Revista da Abem, 21(31), 119-133.

Alves, F. O., Zaninotto, A. L. C., Miotto, E. C, Lucia, M. C. S., \& Scaff, M. (2010). Avaliação da atenção sustentada e alternada em uma amostra de adultos saudáveis com alta escolaridade. Psicologia Hospitalar, 8(2), 89-105. Recuperado de http://pepsic.bvsalud.org/pdf/ph/v8n2/v8n2a06.pdf

Ashendorf, L., L Vanderslice-Barr, J., \& J McCaffrey, R. (2009). Motor tests and cognition in healthy older adults. Applied Neuropsychology, 16(3), 171-176. https://doi.org/10.1080/09084280903098562

Beaty, R. E. (2015). The neuroscience of musical improvisation. Neuroscience \& Biobehavioral Reviews, 51, 108-117. https://doi.org/10.1016/j.neubiorev.2015.01.004

Biasutti, M., \& Mangiacotti, A. (2017). Assessing a cognitive music training for older participants: a randomised controlled trial. International Journal of Geriatric Psychiatry, 33(2), 271-278. https://doi.org/10.1002/gps.4721

Brucki, S. M. D., Nitrin, R., Caramelli, P., Bertolucci, P. H. F., \& Okamoto, I. H. (2003). Sugestões para o uso do mini-exame do estado mental no Brasil. Arquivos de Neuro-Psiquiatria, 61(3), 777-781. https://doi.org/10.1590/50004-2 $82 \times 2003000500014$

Campos, M. C., Silva, M. L., Florêncio, N. C., \& Paula, J. J. (2016). Confiabilidade do teste dos cinco dígitos em adultos Brasileiros. Jornal Brasileiro de Psiquiatria, 65(2), 135-139. https://doi.org/10.1590/0047-2085000000114

Caramelli, P., \& Nitrini, R. (2000). Como avaliar de forma breve e objetiva o estado mental de um paciente? Revista da Associação Médica Brasileira, 46(4), 301-304. https://doi.org/10.1590/\$0104-42302000000400018

Cespón, J., Miniussi, C., \& Pellicciari, M. C. (2018). Interventional programmes to improve cognition during healthy and pathological ageing: cortical modulations and evidence for brain plasticity. Ageing Research Reviews, 43, 81-98. https://doi.org/https://doi.org/10.1016/j.arr.2018.03.001

Chin, T., \& Rickard, N. S. (2012). The Music Use (MUSE) questionnaire: an instrument to measure engagement in music. Music Perception, 29(4), 429-446. https://doi.org/10.1525/mp.2012.29.4.429

Clark, C. N., \& Warren, J. D. (2015). Music, memory and mechanisms in Alzheimer's disease. Brain, 138(8), 2122-2125. https://doi.org/10.1093/brain/awv148 
Clarys, D., Bugaiska, A., Tapia, G., \& Baudouin, A. (2009). Ageing, remembering, and executive function. Memory, 17(2), 158-168. https://doi.org/10.1080/09658210802188301

Coskuner, S., \& Stalheim, J. (2020). Effects of Soundpainting Training on Attention. Journal of History Culture and Art Research, 9(1), 295-304. http://dx.doi.org/10.7596/taksad.v9i1.2307

Costa, P. A. P. (2016). Jogos de improvisação como estratégia para a aquisição de competências técnicas e musicais na aprendizagem da percussão (Dissertação de mestrado não-publicada). Universidade do Minho, Braga, Portugal. Recuperado de http://hdl.handle.net/1822/43931

Fechine, B. R. A., \& Trompieri, N. (2012). Processo de envelhecimento: as principais alterações que acontecem com o idoso com o passar dos anos. Revista Científica Internacional, 1(20), 106-94. Recuperado de http://www.interscienceplace. org/isp/index.php/isp/article/view/196

Garrido, S., Dunne, L., Perz, J., Chang, E., \& Stevens, C. J. (2018). The use of music in aged care facilities: a mixed-methods study. Journal of Health Psychology, 1359105318758861. https://doi.org/10.1177/1359105318758861

Gleizer, S. S., \& Rábanos, N. L. (2017). Influencias del aprendizaje musical en el bienestar de un grupo de personas mayores de 65 años. Acta de Investigación Psicológica, 7(2), 2727-2734. https://doi.org/https://doi.org/10.1016/j. aipprr.2017.06.004

Godoy, S., Dias, N. M., Trevisan, B. T., Menezes, A., \& Seabra, A. G. (2010). Concepções teóricas acerca das funções executivas e das altas habilidades. Cadernos de Pós-Graduação em Distúrbios do Desenvolvimento, 10(1), 76-85. Recuperado de http://editorarevistas.mackenzie.br/index.php/cpgdd/article/view/11178

Kim, S. J., \& Yoo, G. E. (2019). Instrument playing as a cognitive intervention task for older adults: a systematic review and meta-analysis. Frontiers in Psychology, 10(151), 1-13. https://doi.org/10.3389/fpsyg.2019.00151

Klimova, B., Valis, M., \& Kuca, K. (2017). Cognitive decline in normal aging and its prevention: a review on nonpharmacological lifestyle strategies. Clinical Interventions in Aging, 12, 903-910. https://doi.org/10.2147/CIA.S132963

Kratus, J. (1991). Growing with Improvisation. Music Educators Journal, 78(4), 36-40. https://doi.org/10.2307/3398335

Medina, D., \& Barraza, P. (2019). Efficiency of attentional networks in musicians and non-musicians. Heliyon, 5(3), e01315. https://doi.org/10.1016/j.heliyon.2019.e01315

Minayo, M. C. S., \& Firmo, J. O. A. (2019). Longevity: bonus or onus? Ciência \& Saúde Coletiva, 24(1), 4. https://doi. org/10.1590/1413-81232018241.31212018

Moreno, S., \& Farzan, F. (2015). Music training and inhibitory control: a multidimensional model. Annals of the New York Academy of Sciences, 1337(1), 147-152. https://doi.org/10.1111/nyas.12674

Neri, A. L., \& Yassuda, M. S. (2004). Velhice bem-sucedida: aspectos afetivos e cognitivos. Psico-USF, 9(1), 109-110. https://doi.org/10.1590/S1413-82712004000100015

Norton, S., Matthews, F. E., \& Brayne, C. (2013). A commentary on studies presenting projections of the future prevalence of dementia. BMC Public Health, 13(1), 1-5. https://doi.org/10.1186/1471-2458-13-1

Oliveira, A. T. R. (2016). Envelhecimento populacional e políticas públicas: desafios para o Brasil no século XXI. Espaço e Economia, 4(8), 1-20. https://doi.org/10.4000/espacoeconomia.2140

Paula, J. J., Miranda, D. M., Moraes, E. N., \& Malloy-Diniz, L. F. (2013). Mapping the clockworks: what does the Clock Drawing Test assess in normal and pathological aging? Arquivos de Neuro-Psiquiatria, 71(10), 763-768. https://doi. org/10.1590/0004-282X20130118

Pressing, J. (1987). Improvisations: methods and models. In J. Sloboda (Ed.), Generative processes in music (pp.129-178). Oxônia: Oxford University Press.

Rodrigues, A. B., Yamashita, É. T., \& Chiappetta, A. L. M. L. (2008). Teste de fluência verbal no adulto e no idoso: verificação da aprendizagem verbal. Revista Cefac, 10(4), 443-451. https://doi.org/10.1590/S1516-18462008000400004

Sala, G., \& Gobet, F. (2017). When the music's over. Does music skill transfer to children's and young adolescents' cognitive and academic skills? a meta-analysis. Educational Research Review, 20, 55-67. https://doi.org/10.1016/j. edurev.2016.11.005

Särkämö, T. (2018). Cognitive, emotional, and neural benefits of musical leisure activities in aging and neurological rehabilitation: a critical review. Annals of Physical and Rehabilitation Medicine, 61(6), 414-418. https://doi.org/https:// doi.org/10.1016/j.rehab.2017.03.006

Schafer, M. (1992). O ouvido pensante. São Paulo: Unesp.

Seinfeld, S., Figueroa, H., Ortiz-Gil, J., \& Sanchez-Vives, M. V. (2013). Effects of music learning and piano practice on cognitive function, mood and quality of life in older adults. Frontiers in Psychology, 4, 1-13. https://doi.org/10.3389/ fpsyg.2013.00810 
Silva, J. T. S. M. (2020). Práticas musicais através de histórias não letradas. European Review of Artistic Studies, 9(11), 37-47. https://doi.org/10.37334/eras.v11i1.219

Skingley, A., Martin, A., \& Clift, S. (2016). The Contribution of community singing groups to the well-being of older people: participant perspectives from the United Kingdom. Journal of Applied Gerontology, 35(12), 1302-1324. https://doi.org/10.1177/0733464815577141

Slevc, L. R. (2012). Language and music: sound, structure, and meaning. Wiley Interdisciplinary Reviews: Cognitive Science, 3(4), 483-492. https://doi.org/10.1002/wcs.1186

Steibel, N. M. (2016). Propriedades psicométricas da versão brasileira do Teste Comportamental de Memória de Rivermead (RBMT) em idosos (Tese de doutorado não-publicada). Pontificia Universidade Católica do Rio Grande do Sul, Porto Alegre, Brasil. Recuperado de http://tede2.pucrs.br/tede2/handle/tede/7576

Sunderland, T., Hill, J. L., Mellow, A. M., Lawlor, B. A., Gundersheimer, J., Newhouse, P. A., \& Grafman, J. H. (1989). Clock drawing in alzheimer's disease. Journal of the American Geriatrics Society, 37(8), 725-729. https://doi. org/10.1111/j.1532-5415.1989.tb02233.x

Taylor, M. E., Lasschuit, D. A., Lord, S. R., Delbaere, K., Kurrle, S. E., Mikolaizak, A. S., ... Close, J. C. T. (2017). Slow gait speed is associated with executive function decline in older people with mild to moderate dementia: a one year longitudinal study. Archives of Gerontology and Geriatrics, 73, 148-153. https://doi.org/10.1016/j.archger.2017.07.023

Trombetti, A., Hars, M., Herrmann, F. R., Kressig, R. W., Ferrari, S., \& Rizzoli, R. (2011). Effect of music-based multitask training on gait, balance, and fall risk in elderly people. Archives of Internal Medicine, 171(6), 525-533. https://doi. org/10.1001/archinternmed.2010.446

Vazzana, R., Bandinelli, S., Lauretani, F., Volpato, S., Lauretani, F., Di Lorio, A., ... Ferrucci, L. (2010). Trail making test predicts physical impairment and mortality in older persons. Journal of the American Geriatrics Society, 58(4), 719-723. https://doi.org/10.1111/j.1532-5415.2010.02780.x

Vinuto, J. (2014). A amostragem em bola de neve da pesquisa qualitatita: em debate em aberto. Temáticas, 22(44), 201-218.

Wahl, D., Solon-Biet, S. M., Cogger, V. C., Fontana, L., Simpson, S. J., Le Couteur, D. G., \& Ribeiro, R. V. (2019). Aging, lifestyle and dementia. Neurobiology of Disease, 130, e104481. https//doi.org/10.1016/j.nbd.2019.104481

Wamser, E. L., Valderramas, S. R., Paula, J. A., Schieferdecker, M. E., Amarante, T. P., Pinotti, F., ... Gomes, A. R. (2015). Melhor desemprenho no Teste Timed Up and Go está associado a melhor desempenho funcional em idosas da comunidade. Geriatrics Gerontology and Aging, 9(4), 138-43. https://doi.org/10.5327/Z2447-2115201500040003

Received: November 4, 2019

Final version: April 16, 2020

Approved: June 12, 2020 